\title{
Faculty burnout in a large department of pediatrics
}

\author{
BH Davis ${ }^{1}$, SEM Hill ${ }^{2}$, P Fisher ${ }^{3}$, T Nick ${ }^{4}$, Wendy L Ward ${ }^{* 4}$ \\ ${ }^{1}$ Southern Methodist University, Dallas, TX, United States \\ ${ }^{2}$ Episcopal Collegiate School, Little Rock, AR, United States \\ ${ }^{3}$ Louisiana State University, Baton Rouge, LA, United States \\ ${ }^{4}$ Department of Pediatrics, University of Arkansas for Medical Sciences, College of Medicine, Department of Pediatrics, Little \\ Rock, AR, United States
}

Received: December 29, 2014

Accepted: February 11, 2015 Online Published: March 16, 2015

DOI: $10.5430 /$ jha.v4n2p74

URL: http://dx.doi.org/10.5430/jha.v4n2p74

\begin{abstract}
Background: Physician stress is at a heightened level in the midst of a changing health care environment and limited research funding conditions. Burnout of physicians has an impact on their personal health, related institutional health care costs, retention of quality faculty, and patient care and safety. The present study was designed to assess levels of burnout and sources of stress in clinical, educational, and research faculty working in a Department of Pediatrics and a large Children's Hospital setting.

Methods: The self-report Maslach Burnout Inventory was given to the 240 faculty members in a large Department of Pediatrics based at a Children's Hospital as part of a larger faculty development needs survey designed to inform faculty development programming. Participation in the survey was voluntarily, and was presented during a mandatory faculty meeting and then emailed to all faculty so those who were unable to attend could participate. A brief survey on sources of stress, stress-related illness, and wellness programming needs was also administered.

Results: Out of the 240 faculty members, 86 surveys were collected and analyzed ( $36 \%$ response rate). $52 \%$ were female, $84 \%$ were Caucasian. Rank of respondents appeared fairly consistent with overall Departmental distribution (40\% Assistant, $22 \%$ Associate, 34\% Full, 4\% Instructor). 48\% of respondents were Clinical Educators, with 18\% Basic Scientists, 17\% Clinical Attendings, and $16 \%$ Clinical Scientists, also fairly consistent with overall Departmental distributions. Results suggest $65 \%$ of faculty endorse high levels of emotional exhaustion, 56\% high levels of depersonalization, and 100\% felt low levels of personal accomplishment. According to Maslach Burnout Inventory (MBI) cutoff criteria, $94 \%$ of respondents were above the cutoff for Burnout, much higher than recent, published national norms. The most frequently identified top stressors were: lack of connectedness to the institution, administrative responsibilities, time conflicts, clinical workload and general workload. The most frequently identified top stress symptoms experienced were: mood issues, health-related behaviors, and psychosomatic symptoms.

Conclusions: Burnout rates at this institution are higher than national norms. From the data collected, faculty development programs to address coping with burnout and prevention such as strategies to promote resilience to stress will be provided. Faculty will be periodically provided with currently available sources of individual and group support and these will be easily available on the internal website. Institutional changes that may affect burnout rates should also be considered.
\end{abstract}

Key Words: Burnout, Workplace stress, Faculty stress

*Correspondence: Wendy L Ward; Email: wward@uams.edu; Address: Department of Pediatrics, University of Arkansas for Medical Sciences, College of Medicine, Department of Pediatrics, Little Rock, AR,72202-3591, United States. 


\section{Introduction}

Physician stress is at a heightened level in the midst of a changing health care environment. Faculty must cope with increasing clinical workloads ${ }^{[1]}$ different practice models including interprofessional coordination of care, ${ }^{[2]}$ transitions to electronic health records, ${ }^{[3]}$ tightened budgets, ${ }^{[4]}$ and limited research funds to track outcomes. ${ }^{[5]}$

Burnout is defined as exhaustion of physical or emotional strength, a feeling of depersonalization, as well as feeling a low level of personal accomplishment and work satisfaction. ${ }^{[6]}$ Professional burnout is becoming widely prevalent among physicians across the country. ${ }^{[6]}$ Burnout of faculty has an impact on their personal health, ${ }^{[7]}$ related institutional health care costs, ${ }^{[8]}$ retention of quality faculty,${ }^{[9]}$ and patient care and safety. ${ }^{[10]}$ In fact, burnout has an impact on clinician-rated and objective ratings of patient safety including higher mortality ratios. ${ }^{[11]}$ "Research shows that approximately $15 \%$ to $20 \%$ of physicians will have mental health problems at some point in their careers". ${ }^{[12]}$ There are many factors that have been linked to faculty burnout including patient load, ${ }^{[13]}$ electronic health care records, ${ }^{[3]}$ administrative responsibilities, ${ }^{[14]}$ long hours, ${ }^{[15]}$ and the critical decisions they must make on a daily basis. ${ }^{[16]}$

The present study was designed to assess levels of burnout and sources of stress in clinical, educational, and research faculty (physicians and doctoral research faculty) working in a Department of Pediatrics at a large Children's Hospital setting. The study assessed A survey was created to assess current burnout rates, as well as top stressors and top symptoms of stress. This examination is important so that future prevention and intervention wellness programs to promote resilience and individual stress management skill development can be put in place. This programming should address both the cause of the problem and allow members to learn the needed skills to cope in a high-stress environment. Not only was the goal to address the individuals, but also provide incentive to address any institutional/systematic sources of stress.

\section{Methods}

This survey was distributed to 240 faculty members in a large Department of Pediatrics working in a freestanding Children's Hospital as part of a larger survey about faculty development programming and needs. The Maslach Burnout Inventory-Human Services Survey (MBI-HSS) was included as an assessment of work-related stress. This is a 22-item survey that has shown adequate reliability and validity data ${ }^{[17,18]}$ and has been used by a wide variety of health professionals including physicians ${ }^{[6,18,19]}$ and shows discriminant validity in distinguishing from depression. ${ }^{[20]}$ In addition, free response questions were asked about the faculty members' top three sources of stress and top three signs/symptoms of stress.

Published by Sciedu Press
The survey was presented to the faculty for completion in a paper-and-pencil format at the beginning of a mandatory faculty meeting so that they could complete it during the meeting and turn it in anonymously afterward. The agenda of the meeting involved celebrating those recently promoted/tenured and was an upbeat meeting. Since not all faculty attended the meeting and/or completed the questionnaire, follow-up requests were emailed to faculty who could print and return the survey via interoffice email to maintain anonymity. No personal identifiers were collected and responses were anonymous. Data was entered by a research assistant and all items were checked for data entry accuracy. Institutional IRB review and approval was obtained.

\section{Results}

The response rate of the study was $36.25 \%$ ( 87 of 240), which is an acceptable response rate for a survey of this nature given other surveys of busy physicians. ${ }^{[6]}$ The resulting sample is a representative sample of the overall faculty population in terms of gender, race, rank, and academic track (see Table 1). Information regarding partners and children was also obtained.

Table 1: Sample demographics

\begin{tabular}{llll}
\hline Item & & Frequency & Percent \\
\hline \multirow{2}{*}{ Gender } & Male & 41 & 47.67 \\
& Female & 45 & 52.33 \\
& Asian & 2 & 2.355 \\
& Asian American & 9 & 10.59 \\
& Caucasian & 71 & 83.53 \\
& Hispanic & 3 & 3.53 \\
Level & Assistant & 34 & 39.53 \\
& Associate & 19 & 22.09 \\
& Full & 29 & 33.72 \\
& Instructor & 4 & 4.65 \\
& Attending & 15 & 17.44 \\
& Basic & 16 & 18.60 \\
& Educator & 41 & 47.67 \\
& Scientist & 14 & 16.28 \\
& Partnered & 73 & 83.91 \\
& Not Partnered & 12 & 13.79 \\
& $<12$ yrs at home & 26 & 30.23 \\
& Teenagers at home & 6 & 6.98 \\
& Grown children & 21 & 24.42 \\
& <12 yrs \& teenagers & 7 & 8.14 \\
& Teenagers \& grown & 6 & 6.98 \\
& None & 20 & 23.29 \\
\hline \multirow{5}{*}{ Children } & & &
\end{tabular}

Results of the MBI (see Table 2) found a very high percentage $(94 \%)$ of faculty members had a clinical level of burnout, with high percentages for each of the subscales (emotional exhaustion, low sense of personal accomplishment, and depersonalization). 
Table 2: Maslach Burnout Inventory at children's hospital

\begin{tabular}{llll}
\hline Item & & Frequency & Percent \\
\hline \multirow{2}{*}{ Burnout } & No & 5 & 6.02 \\
& Yes & 78 & 93.98 \\
Exotional & Low & 4 & 4.82 \\
& Intermediate & 26 & 31.33 \\
Depersonalization & High & 53 & 63.86 \\
& Low & 2 & 2.41 \\
Personal & Intermediate & 6 & 7.23 \\
Accomplishment & High & 75 & 90.36 \\
& Low & 83 & 100.00 \\
& Intermediate & 0 & 0.00 \\
& High & 0 & 0.00 \\
\hline
\end{tabular}

Respondents were asked free response questions asking them to list their top three sources of stress and their top three signs/symptoms of stress. Results were tabulated and categories of responses identified. Results of the top 3 for each question are shown in Table 3.

\section{Discussion}

This study highlights the reality of working in the highstress environment of academic medicine. The faculty in this particular department shows a much higher percentage of Burnout than the national average. ${ }^{[6]}$ A majority of faculty feel depersonalized, emotionally exhausted, and have a low sense of personal accomplishment. This can have negative implications both on the individual (low work satisfaction, mental health, physical health) but also on the institution (lower productivity, higher health care costs for workers, lower retention rates). Wellness programming is clearly needed for this diverse group of faculty. This survey is a call to action for wellness programming and referral sources for individual intervention, but also to investigate more clearly the sources of stress and intervene on an institutional level. Many faculty report connectedness/support, administrative responsibilities, and time management/workload demands as key issues.

This survey occurred in the context of leadership change (the CEO of the children's hospital was retiring and replacement unknown; the Deanship of the College of Medicine was in transition), financial issues had arisen at the academic institutional level resulting in budget cuts and increased productivity demands throughout the College of Medicine, electronic health record upgrades were causing safety and clinical care issues, as well as the overall context of the process of healthcare reform. The timing of the survey, thus, was likely at a very high level of stress and may not be reflective of the typical stress level experienced by faculty in this department. At minimum, this survey identified clear faculty needs and as such helps justify departmental and institutional support for wellness programming. It is not yet clear how relevant the results of this survey are to other de- partments within our institution or across the country. Future research should investigate burnout and faculty stress sources and symptoms in other academic medicine institutions.

Table 3: Stressors and symptoms among faculty

\begin{tabular}{lll}
\hline Item & & Frequency \\
\hline & Lack of Authority & 4 \\
& Burn Out & 5 \\
& Funding & 5 \\
& Scholarly Activity & 7 \\
& Understaffed & 7 \\
Top 3 Stressors & Other & 10 \\
& Workload (General) & 12 \\
& Clinical Workload & 14 \\
& Time Conflict & 16 \\
& Admin Responsibilities & 17 \\
& Connectedness & 22 \\
& Other & 3 \\
& Cognitive & 9 \\
Top 3 Symptoms & Psychosomatic & 20 \\
& Health Behaviors & 35 \\
& Mood Issues & 42 \\
\hline
\end{tabular}

This study was an effective measure in gathering the muchneeded information from the faculty. However, out of the 240 faculty members in the Department of Pediatrics, only 87 completed surveys. We know that the respondents were from across all ranks, tracks, genders, and racial groups, and suspect the results are fairly representative of this diversity. However, it is possible that a response bias skewed the results; for instance, if only the faculty who were burned out completed the survey. Since the survey was contained within a larger survey on faculty development needs we feel that this is less likely but still possible. Further, the timing of the survey was such that a confluence of factors increased the stress level higher than is typical.

Future research should look at the issue of burnout more comprehensively, with comparisons across samples such as adult/pediatric, inpatient/outpatient, or across institutions nationally. For instance, we know from a national survey of American Medical Association members that rates differ according to subspecialty, ${ }^{[6]}$ but more information is needed on why these differences exist and how to reduce burnout rates in these areas. Additional questions related to stress would be helpful beyond simply burnout as well-self-report measures of perceived stress and job satisfaction, for instance, as well as objective measurements of stress or performance. The relationship between patient safety and emotional and/or physical exhaustion is also critical; as interventions to improve burnout may have corresponding improvements in patient care quality and infection/mortality rates. Longitudinal tracking of faculty stress and burnout as well as effectiveness of burnout prevention and intervention programs is needed.

ISSN 1927-6990 E-ISSN 1927-7008 


\section{References}

[1] van Olmen J, Ku GM, Bermejo R, et al. The growing caseload of chronic life-long conditions calls for a move towards full selfmanagement in low-income countries. Globalization and Health. 2011; 7: 38. PMid: 21985187. http://dx.doi.org/10.1186/1 744-8603-7-38

[2] Tomcavage J, Garrett MB. Care Coordination: Case managers "connect the dots" in new delivery models. Commission for Case Manager Certification. 2009; 1: 1-8.

[3] Baron RJ, Fabens EL, Schiffman M. et al. Electronic Health Records: Just around the Corner? Or over the Cliff?. Annals of Internal Medicine. 2005; 143: 222-226. PMid: 16061920. http: // dx.doi.org/10.7326/0003-4819-143-3-200508020-00008

[4] Saver C. OR leaders face tightened budgets, loss of benefits in wake of recession. OR Manager. 2009; 1: 10-5.

[5] Moses H, Dorsey ER. Biomedical Research in an Age of Austerity. JAMA. 2012; 308(22): 2341-2. http://dx.doi.org/10.1001/j ama. 2012.14846

[6] Shanafelt TD, Boone S, Tan L, et al. Burnout and Satisfaction With Work-Life Balance Among US Physicians Relative to the General US Population. Archives of Internal Medicine. 2012; 172: 13771385. PMid: 22911330. http://dx.doi.org/10.1001/archi nternmed.2012.3199

[7] Panagopoulou E, Montogomery A, Benos A. Burnout in internal medicine physicians: Differences between residents and specialists. Eur J Intern Med. 2006; 3: 195-200. PMid: 16618453. http: //dx.doi.org/10.1016/j.ejim.2005.11.013

[8] Studer Group. Physician burnout: Preparing for a "perfect storm". Straight A Review. February. 2012; 1-7.

[9] Pololi L, Knight S. Mentoring faculty in academic medicine. A new paradigm? J Gen Intern Med. 2005; 20(9): 866-70. PMid: 16117759. http://dx.doi.org/10.1111/j.1525-1497.2005 $.05007 . \mathrm{x}$

[10] Arora M, Asha S, Chinnappa J, et al. Review Article: Burnout in emergency medicine physicians. Emergency Medicine Australasia. 2013. http://dx.doi.org/10.1093/heapol/czh031
[11] Welp A, Meier LL, Manser T. Emotional exhaustion and workload predict clinician-rated and objective patient safety. Front Psychol. 2015; 5: 1573. PMid: 25657627. http://dx.doi.org/10.3389 /fpsyg. 2014.01573

[12] Zwack J, Schweitzer J. If Every Fifth Physician Is Affected by Burnout, What About the Other Four? Resilience Strategies of Experienced Physicians. Academic Medicine. 2013; 88: 1-8. PMid: 23348093. http://dx.doi.org/10.1097/ACM.0b013e3 $18281696 \mathrm{~b}$

[13] Ozge Tayfur, Mahmut Arslan. The Role Of Lack Of Reciprocity, Supervisory Support, Workload And Work-Family Conflict On Exhaustion: Evidence From Physicians, Psychology, Health \& Medicine. 2013. http://dx.doi.org/10.1080/13548506.20 12.756535

[14] Van Dyke A, Seger AM. Finding, keeping, and revitalizing the meaning in family medicine. Int J Psychiatry Med. 2013; 45(4): 323-31. PMid: 24261266. http://dx.doi.org/10.2190/PM. 45 .4. C

[15] Ozyurt A, Hayran O, Sur H. Predictors of burnout and job satisfaction among Turkish physicians. QJ Med. 2006; 99:161-169. PMid: 16490757. http://dx.doi.org/10.1093/qjmed/hc1019

[16] Wright JG, Khetani N, Stephens D. Burnout among faculty physicians in an academic health science centre. Paeditr Child Health. 2011; 16(7): 409-413.

[17] Maslach C, Jackson, SE. The measurement of experience burnout. Journal of Occupational Behaviour. 1981; 29: 9-113.

[18] Rafferty J, Lemkau JP, Purdy RR, et al. Validity of the Maslach burnout inventory for family practice physicians. Journal of Clinical Psychology. 1986; 42 (3): 488-492. http ://dx .doi.org/10.1002/1097-4679(198605)42: 3<488: : AID-JCLP2270420315>3.0.CO;2-S

[19] Hill JD, Smith RJ. Monitoring stress levels in postgraduate medical training. The Laryngoscope. 2009; 119: 75-78. PMid: 19117300. http://dx.doi.org/10.1002/lary. 20013

[20] Leiter M, Durup J. The discriminant validity of burnout and depression: a con-firmatory factor analytic study. Anxiety Stress Coping. 7: 357-373. http://dx.doi.org/10.1080/106158094082493 57 